\title{
Energy and Exergy Analysis for Low-Temperature Refrigeration System for Biogas Upgrading
}

\author{
Joseph Bassila $^{1}$, Joseph Toubassy ${ }^{1}$, Denis Clodic ${ }^{1}$ and Amélie Danlos ${ }^{2}$ \\ 1. Cryo Pur, 3 rue de la Croix Martre 91120, Palaiseau, France \\ 2. Conservatoire National des Arts et Métiers, Laboratoire de Chimie Moléculaire, Génie des Procédés Chimiques et Energétique \\ (CNAM-CMGPCE EA 7341), 292 rue Saint Martin 75003, Paris, France
}

Received: July 19, 2016 / Accepted: August 02, 2016 / Published: January 31, 2017.

\begin{abstract}
Low-temperature refrigeration system for biogas upgrading has been developed by the Cryo Pur company based on cooling biogas in three steps: Removing most of the water content at $-40{ }^{\circ} \mathrm{C}$, removing siloxanes and $\mathrm{SVOCs}$ at $-85{ }^{\circ} \mathrm{C}$ and frosting $\mathrm{CO}_{2}$ at temperatures varying from $-90{ }^{\circ} \mathrm{C}$ to $-120{ }^{\circ} \mathrm{C}$. This process transforms biogas containing typically $60 \%$ methane, $35 \% \mathrm{CO}_{2}, 5 \%$ water vapor in methane containing $2.5 \%$ of $\mathrm{CO}_{2}$. This paper studies how a single low-temperature refrigeration system is able to cool biogas with an indirect system using low-temperature heat-transfer fluids. The exergy study defines the exergy losses and served as guidance for the energy/pinch analysis that is used for the design of the heat-exchanger series and the appropriate heat recovery. An optimal system could save up to $40 \%$ of the electric consumption of the refrigeration system.
\end{abstract}

Key words: Biogas, upgrading, exergy analysis, pinch analysis, refrigeration cascade.

\section{Nomenclature}

SVOC Sulfuric volatile organic compound

HTF Heat transfer fluid

$P \quad$ Power $(\mathrm{kW})$

$\dot{m} \quad$ Flowrate $(\mathrm{kg} / \mathrm{s})$

$T \quad$ Temperature (K)

$s \quad$ Entropy $(\mathrm{kJ} / \mathrm{kg} \cdot \mathrm{K})$

Ex Exergy $(\mathrm{kJ})$

w Work (kJ)

$H \quad$ Enthalpy $(\mathrm{kJ} / \mathrm{kg})$

$Q \quad$ Heat $(\mathrm{kJ} / \mathrm{kg})$

$\Delta \quad$ Difference

out Outlet

in Inlet

sol Solid

lat Latent

sen Sensible

a Ambient

i Index

Corresponding author: Joseph Bassila, Ph.D., research fields: energy and environment.

\section{Introduction}

Biogas is produced from organic waste by means of bacteria in an anaerobic environment. Bigadan [1] expedites this process at an operating temperature of $38{ }^{\circ} \mathrm{C}$ (mesophilic) or $52{ }^{\circ} \mathrm{C}$ (thermophilic) in the plant's digester. The biogas plant receives all kinds of organic waste - typically livestock manure and organic industrial waste. The manure and waste are mixed in the plant's receiving tank before being heated to $38-52{ }^{\circ} \mathrm{C}$ and pumped into the digester in which the biogas is produced.

Ryckebosch et al. [2] mentioned many techniques that have been developed to remove $\mathrm{H}_{2} \mathrm{~S}, \mathrm{H}_{2} \mathrm{O}$, trace components and $\mathrm{CO}_{2}$ from biogas. IEA GHG [3] introduce the cryogenic separation to capture the carbon dioxide from flue-gas stream by condensation.

Cryo Pur [4] developed a low-temperature refrigeration system for biogas upgrading. This system is based on 3 main steps. The biogas passes through a first subsystem at $-40{ }^{\circ} \mathrm{C}$ to remove mainly water 
Table 1 Composition of biogas.

\begin{tabular}{lll}
\hline Component & Formula & Concentration \\
\hline Methane & $\mathrm{CH}_{4}$ & $50-75 \%$ \\
Carbon dioxide & $\mathrm{CO}_{2}$ & $25-45 \%$ \\
Water vapor & $\mathrm{H}_{2} \mathrm{O}$ & $2-7 \%$ \\
Hydrogen sulphide & $\mathrm{H}_{2} \mathrm{~S}$ & $0.002-2 \%$ \\
Nitrogen & $\mathrm{N}_{2}$ & $<2 \%$ \\
Ammonia & $\mathrm{NH}_{3}$ & $<1 \%$ \\
Hydrogen & $\mathrm{H}_{2}$ & $<1 \%$ \\
Trace gases & & $<2 \%$ \\
\hline
\end{tabular}

vapor, then a second subsystem at $-85^{\circ} \mathrm{C}$ separates all components in order to obtain at exit $40 \% \mathrm{CO}_{2}$ and $60 \% \mathrm{CH}_{4}$ [5]. In the third sub-system, $\mathrm{CO}_{2}$ is captured by frosting. After this last step, upgraded methane (98\% purity) is liquefied then used as fuel, in the industry and in a natural gas grid injection. In this paper a single low-temperature refrigeration system using low-temperature heat-transfer fluid is studied and compared to four refrigeration sub-systems.

The pinch analysis is used in order to identify possible transfers between heats sources and heat sinks.

\section{Energy Study}

\subsection{Separation of $\mathrm{H}_{2} \mathrm{O}$ and $\mathrm{CO}_{2}$}

The required cooling capacities to remove water and carbon dioxide from methane are first calculated. In order to be generic, the dry biogas mass flow rate is fixed at $1 \mathrm{~kg} / \mathrm{s}$. Water is removed at two temperature levels $-40{ }^{\circ} \mathrm{C}$ and $-85{ }^{\circ} \mathrm{C}$ in the current system, but for the new system, the biogas will be cooled from $20{ }^{\circ} \mathrm{C}$ to $-85{ }^{\circ} \mathrm{C}$ in one stage as shown in Fig. 1 . The biogas enters at volumetric composition of $56.8 \%$ methane, $37.7 \%$ carbon dioxide and $5.5 \%$ water, and exits at $60 \%$ methane and $40 \%$ carbon dioxide. For $\mathrm{CO}_{2}$ removal, the heat transfer fluid cools the biogas at $-116{ }^{\circ} \mathrm{C}$ in order to reduce the $\mathrm{CO}_{2}$ content at $2 \%$. As shown in Fig. 2, the volumetric composition is $98 \%$ methane and $2 \%$ carbon dioxide, then methane is liquefied at 1.5 MPa as shown in Fig. 3.

The enthalpy difference of each fluid is calculated using Eq. (1) while heat exchanged is calculated using Eq. (2).

$$
\begin{gathered}
Q=\Delta H_{\text {sen }}+H_{\text {lat }} \\
P=\dot{m}_{\text {exit }} \cdot \Delta H_{\text {sen }}+\dot{m}_{\text {sol }} \cdot H_{\text {lat }}
\end{gathered}
$$

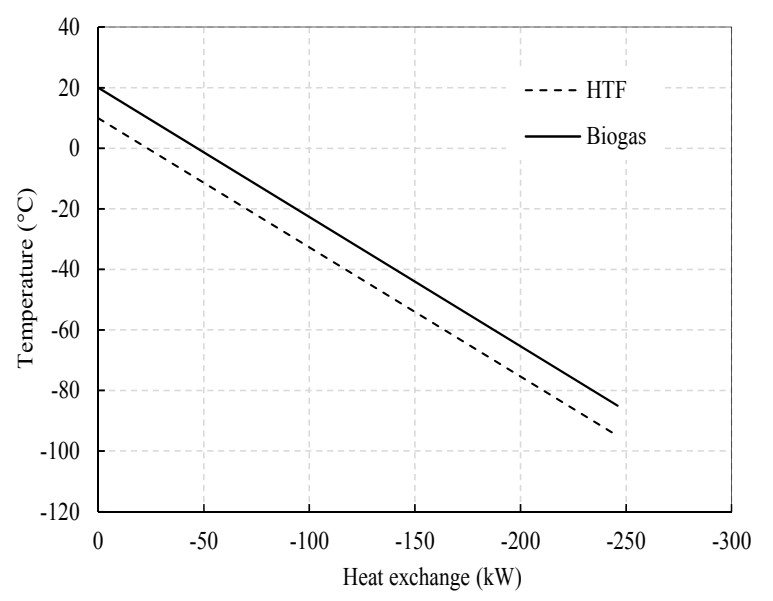

Fig. 1 T-P diagram for removing water.

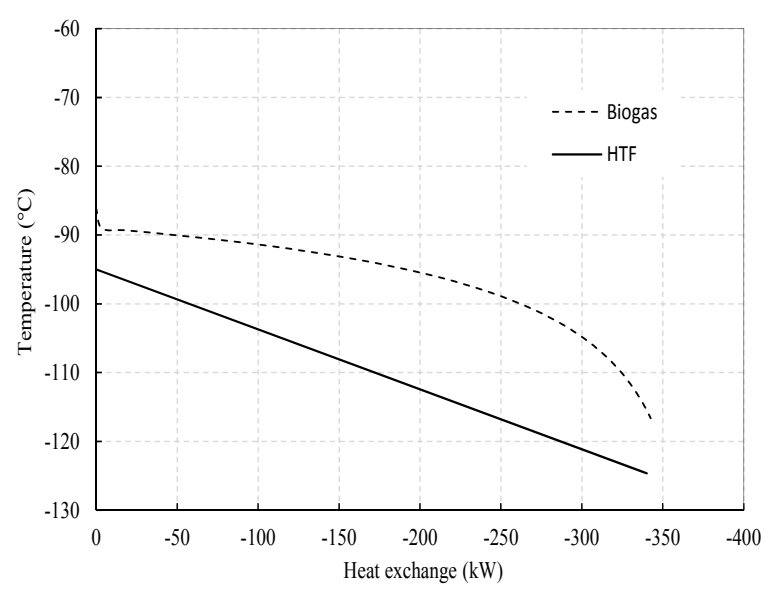

Fig. $2 \quad$ T-P diagram for removing carbon dioxide.

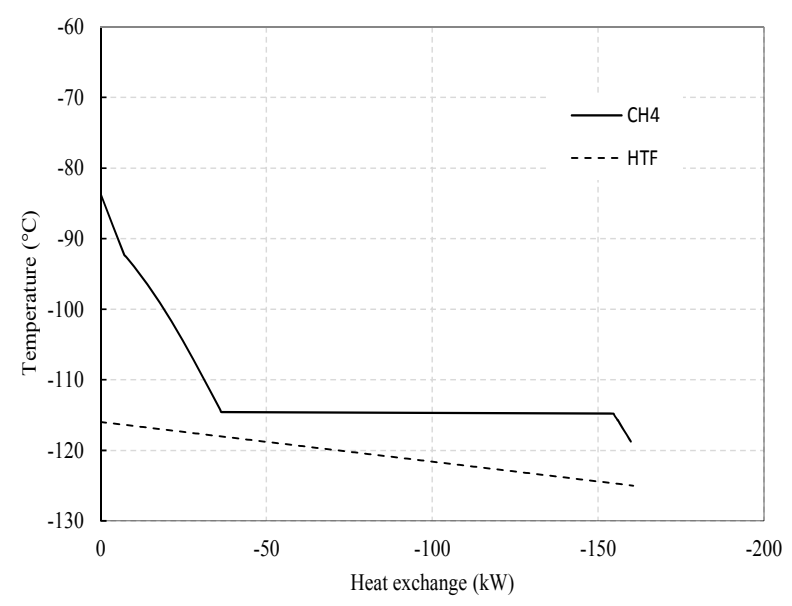

Fig. 3 T-P diagram for liquefied biomethane. 
The heat exchanged $(P)$ is function of the flow rate at the exit of heat exchanger ( $\left.\dot{m}_{\text {exit }}\right)$, the sensible enthalpy difference ( $\Delta H_{\text {sen }}$ ), the mass of frost captured $\left(\dot{m}_{\text {sol }}\right)$ and the latent heat of sublimation $\left(H_{\text {lat }}\right)$.

\subsection{The Strategy for Energy Recovery (Theoretical} Gain)

The system works using Frosting/Defrosting heat exchangers for water and $\mathrm{CO}_{2}$. The current Cryo Pur system defrosts carbon dioxide above the triple point $\left(-56.6{ }^{\circ} \mathrm{C}\right.$, and $\left.0.52 \mathrm{MPa}\right)$. The new strategy recovers the energy by sublimation of carbon dioxide in order to cool the heat-transfer fluid and by so reducing the cooling capacity of the refrigeration system.

The available energy recovery by sublimation of carbon dioxide is shown in Fig. 4. $\mathrm{CO}_{2}$ in gaseous state passes through two heat exchangers to cool the heat-transfer fluid as shown in Figs. 5 and 6.

So the theoretical gain is about $336 \mathrm{~kW}$ for $1 \mathrm{~kg} / \mathrm{s}$ of dry biogas.

\section{Exergy Losses with Low Temperature Heat Transfer Fluid}

The exergy Eq. (3) is the maximum theoretical work than can be obtained from an amount of energy [6].

$$
E x=\dot{m}\left(\Delta h-T_{a} \cdot \Delta s\right)+\sum_{i} W_{i}+\sum_{i} Q_{i} \cdot\left(1-\frac{T_{a}}{T_{i}}\right)
$$

It is calculated as a function of the mass flow rate ( $\dot{m})$, the enthalpy difference $(\Delta h)$, the entropy difference $(\Delta s)$, the mechanical work $\left(W_{i}\right)$, the heat transferred $\left(Q_{i}\right)$, the ambient temperature $\left(T_{a}\right)$ and the fluid temperature $\left(T_{i}\right)$.

To improve the heat exchange in the system, exergy losses should be minimized.

Comparing many low-temperature HTF (heat-transfer fluids), they have the same exergy losses. We conclude that the only difference between them is their flow rates in each heat exchanger. So they are compared by their heat capacity; once the heat capacity is higher, the flow rate decreases, the power and the consumption of the cryogenic pump decrease.

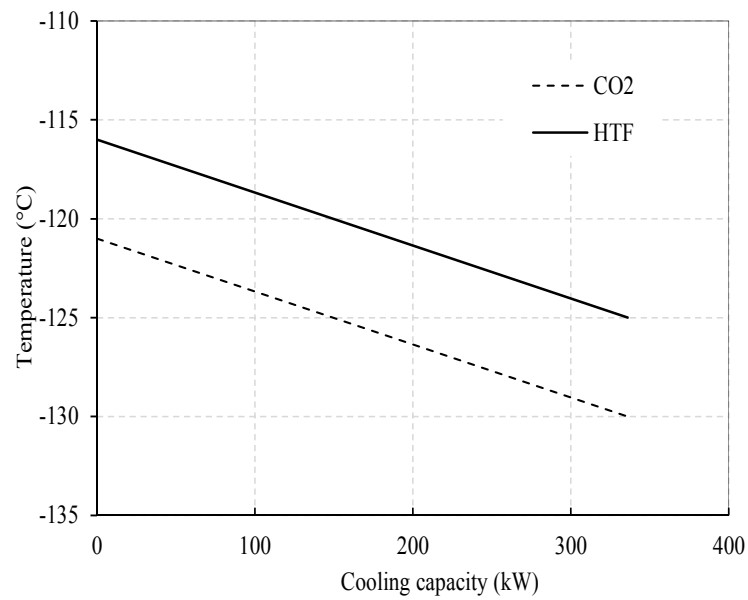

Fig. $4 \quad T$-P diagram for recovering power by sublimation of carbon dioxide.

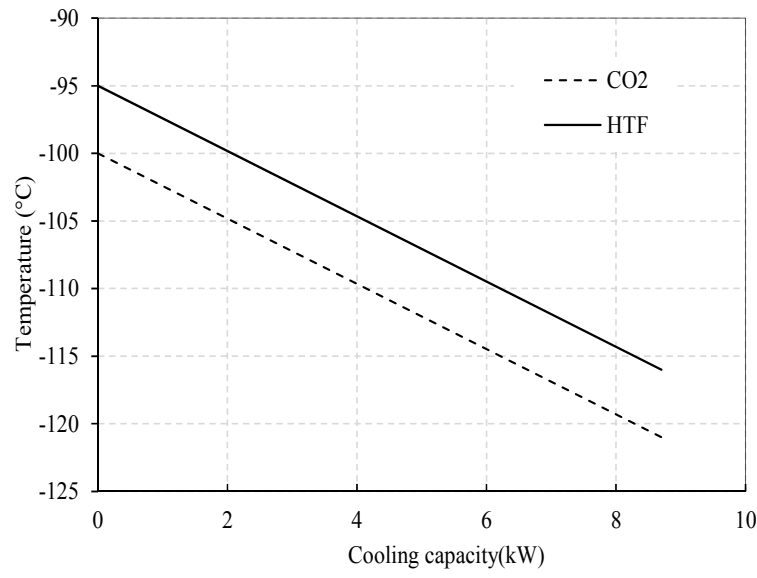

Fig. 5 T-P diagram for heat recovery.

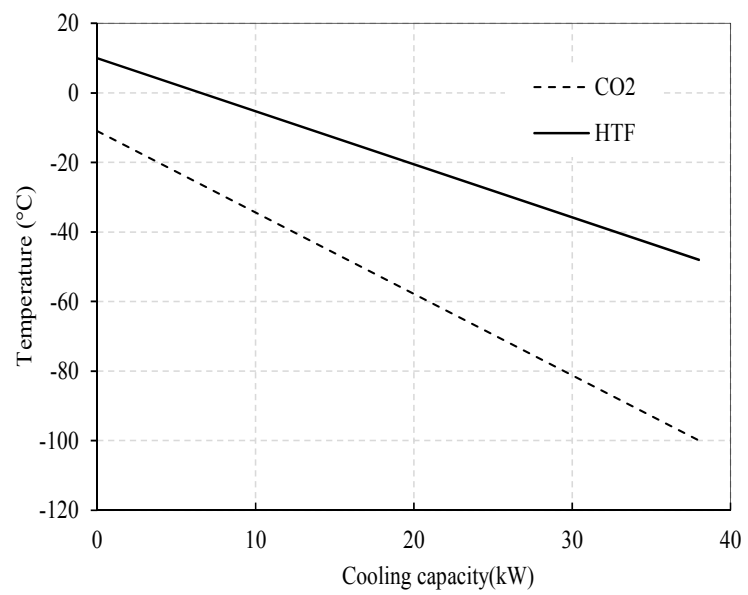

Fig. $6 \quad T$-P diagram for heat recovery. 


\section{Energy Analysis}

In order to obtain the minimum power consumption of the system, the required energy to upgrade the biogas and liquefy the methane is calculated, then the recovered energy from sublimation of carbon dioxide is calculated from $-130{ }^{\circ} \mathrm{C}$ to $-11^{\circ} \mathrm{C}$.

The HTF flows returning from the different subsystems at different levels of temperature are mixed. Using Eq. (4), the total enthalpy $(h)$ is calculated as function of the mass flow rates $\left(\dot{m}_{l}\right)$ and the enthalpy at each level temperature $\left(h_{i}\right)$, so the average temperature of the HTF flows is determined and then the required cooling capacity of the refrigeration system is calculated.

$$
h=\frac{\sum_{i}\left(\dot{m}_{i} \cdot h_{i}\right)}{\sum_{i} \dot{m}_{i}}
$$

Fig. 7 represents the $T-P$ diagram, the possible heat recovery and the necessary cooling capacity to remove water and carbon dioxide, to liquefy methane, and the theoretical available energy to be recovered by $\mathrm{CO}_{2}$ sublimation from $-130{ }^{\circ} \mathrm{C}$ to $-11{ }^{\circ} \mathrm{C}$. Referring to Fig. 7, for the reference flow of $1 \mathrm{~kg} / \mathrm{s}$ of biogas, the refrigeration system should generate $276 \mathrm{~kW}$ for biogas upgrading and methane liquefaction.

In order to optimize the heat-exchanger network for heat recovery, the Pinch analysis is carried out. The Pinch analysis aims at identifying the heat recovery opportunities by heat exchange in complex thermal processes. Linhoff [7] developed a graphical method to calculate the minimum energy requirement of a process and design the heat recovery exchanger network. The possible heat exchange is limited by the approach temperature between the hot and the cold stream in the heat exchanger. Marechal [8] shows that when the approach temperature is small, the energy savings are high but the investment required is also high; when the approach temperature is higher, the investment decreases while the operating costs increase. The minimum temperature approach is the smallest temperature difference between the hot and the cold streams in the heat exchanger. The minimum temperature difference can be used as a parameter to determine the optimal size of the heat exchanger.

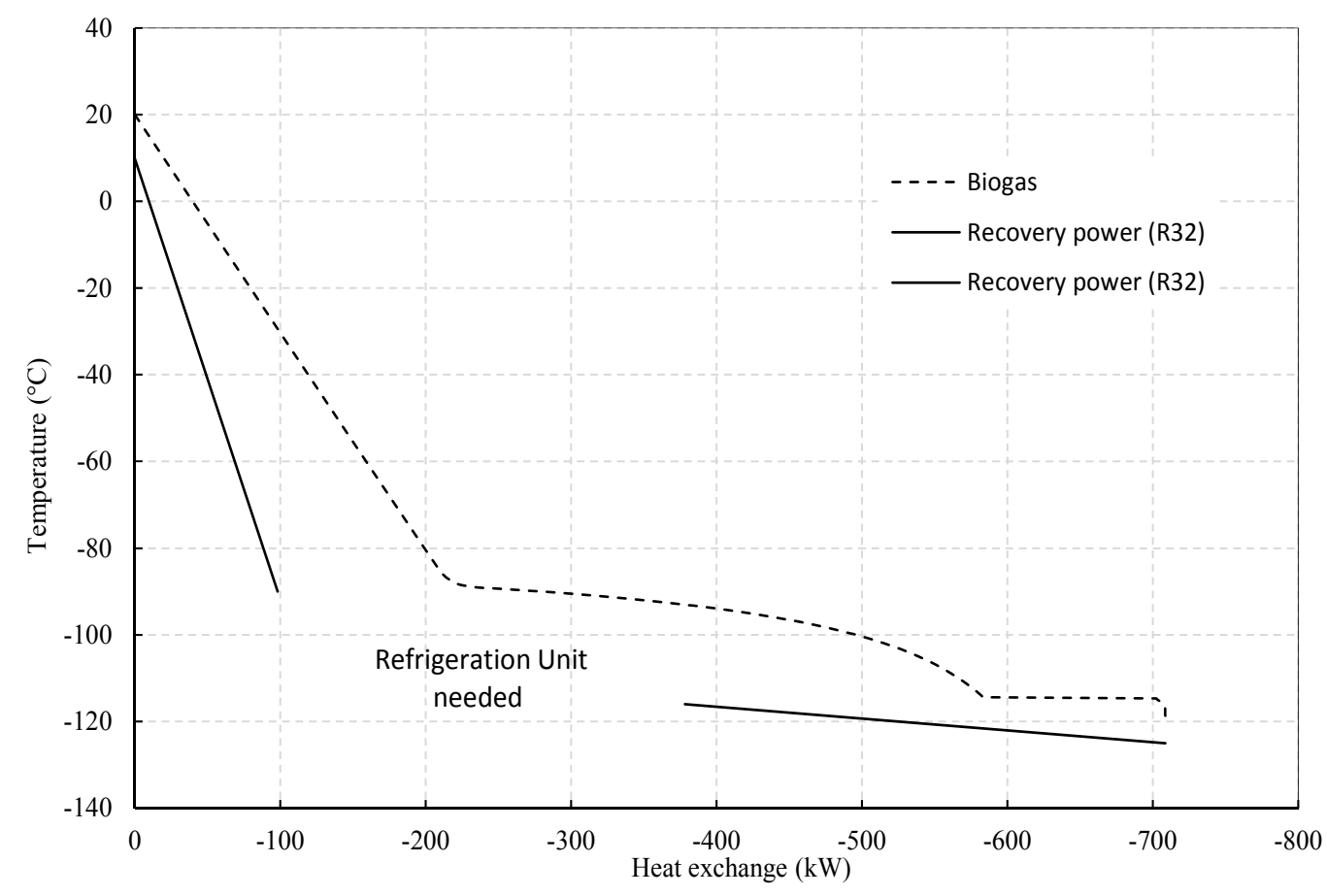

Fig. 7 Energy recovery in the $T$-P diagram. 


\section{Results and Conclusions}

In the current Cryo Pur system, $0.63 \mathrm{~kW} / \mathrm{Nm}^{3}$ of biogas at $55 \% \mathrm{CH}_{4}$ and $45 \% \mathrm{CO}_{2}$ is needed to obtain methane with $0.98 \%$ purity, with the new recovery option, $0.36 \mathrm{~kW} / \mathrm{Nm}^{3}$ could be reached. So the new strategy for Cryo Pur could save up to $40 \%$ of the electrical consumption.

This new architecture requires many developments in order to limit pressure losses and to define the optimal sublimation pressures.

\section{Acknowledgement}

This work was supported by Cryo Pur and CNAM (Conservatoire National des Arts et Métiers). Thank Georges Descombes for his comments that greatly improved the manuscript.

\section{References}

[1] Bigadan. 2001. "Biogas Technology.” http://bigadan.com /p/biogas-technology/how-to-make-biogas.

[2] Ryckebosch, E., Drouillon, M., and Vervaeren, H. 2011. "Techniques for Transformation of Biogas to Biomethane." Biomass and Bioenergy 35 (5): 1633-45.

[3] IEA GHG. 1993. The Capture of Carbon Dioxide from Fossil Fuel Fired Power Stations, Cheltenham, UK.

[4] Cryo Pur. 2015. "Valorize Biogas with Bio-LNG and Bio- $\mathrm{CO}_{2}$." http://www.cryopur.com/.

[5] Gerlach et al. 2013. Sustainable Biogas Production. Frankfurt, Germany: FiBL Projekte GmbH Publisher.

[6] Lallemand, A. 2007. Energie, éxergie, économie, thermo-économie. Centre de thermique de Lyon, UMR 5008 CNRS, INSA, UCBL, France.

[7] Linhoff. 1970. "Introduction to Pinch Analysis." in Developments in Design of Thermal System, edited by Boshm, R. F. Cambridge: Cambridge University Press, 122-38.

[8] Marechal. 2007. Pinch Analysis. Ecole Polytechnique Fédérale de Lausanne, Switzerland. 